Discussion Paper No. 940

\title{
CAPITAL HETEROGENEITY \\ AS A SOURCE OF \\ COMPARATIVE ADVANTAGE: \\ PUTTY-CLAY TECHNOLOGY \\ IN A RICARDIAN MODEL
}

Hirokazu Ishise

June 2015

The Institute of Social and Economic Research

Osaka University

6-1 Mihogaoka, Ibaraki, Osaka 567-0047, Japan 


\title{
Capital Heterogeneity as a Source of Comparative Advantage: Putty-Clay Technology in a Ricardian Model
}

\author{
Hirokazu Ishise*
}

June 23, 2015

(First version: February 19, 2013)

\begin{abstract}
I consider how heterogeneity in capital goods affects international trade patterns, and I show a novel source of comparative advantage: the magnitude of capital goods heterogeneity. Capital goods are heterogeneous in their vintage and productivity, and due to capacity constraints, only productive capital goods are activated in the equilibrium. Through this selection, the distribution of capital goods determines the industrylevel productivity: industry-level productivity is higher in an industry with relatively larger variation in capital goods, and hence in a perfectly competitive two-country, two-good, two-factor equilibrium, the industry has Ricardian comparative advantage. An extension of the model, including fixed trade cost, describes a sorting situation in which the most productive production units (which are generally newer vintage) export, the moderately productive units serve the domestic market, and the least productive units (older) do not operate.
\end{abstract}

*Institute of Social and Economic Research, Osaka University. Address: 6-1 Mihogaoka, Ibaraki, Osaka 567-0047, Japan; Phone: +81-6-6879-8581; Email to: ishise@iser.osaka-u.ac.jp; I would like to thank comments by two anonymous referees, Marianne Baxter, Jonathan Eaton, Taiji Furusawa, Simon Gilchrist, François Gourio, Samuel Kortum, Noriaki Matsushima, Ray Riezman, and seminar/conference participants at Kansai, Kobe, Kyoto, Osaka (Econ and ISER), Tohoku, Yokohama National, Spring 2013 Midwest International Trade meeting, Spring 2013 JEA meeting, and 2014 Asian Meeting of the Econometric Society. This work is supported by JSPS KAKENHI Grant Number 26885043. All errors are mine. 
Keywords: Ricardian trade model; Putty-clay technology; Vintage capital; Capacity utilization rate; Sorting in destination.

JEL Codes: F11, D24, E22, E23.

\section{Introduction}

While investment drives several aspects of aggregate economy, trade models frequently abstract investment decisions regarding capital goods by considering an endowment economy. In models that include investment decision, capital goods are commonly assumed to be homogeneous. However, an important empirical aspect of capital goods is heterogeneity in productivity. Some capital goods are more productive than others within an industry.

This paper considers the role of investment and productivity heterogeneity of capital goods in the pattern of international trade. Specifically, I introduce putty-clay production technology in the style of Gilchrist and Williams (2000, 2004, 2005) into an international trade model considered by Baxter (1992), and discover that the magnitude of heterogeneity in capital goods is a source of Ricardian comparative advantage.

Baxter (1992) includes endogenous capital accumulation, intertemporal optimization and neoclassical production function in the classical "2 by 2 by 2" (two-country, two-good, and two-factor) international trade model. She shows that in the steady-state of the dynamic economy, the pattern of comparative advantage is described as a Ricardian model, compared to the classical endowment "2 by 2 by 2 " model that implies a Heckscher-Ohlin trade pattern. Intuitively, since returns to investment are determined by the user cost, which is ultimately determined by the subjective discount factor and the capital depreciation rate, the amount of capital is fully adjusted so that the returns to investment are equalized across industries. As a result, the economy effectively has only one input (labor) as in the Ricardian model. The relative price of goods under autarky is determined by the ratio of productivities across industries, and this relative price predicts the pattern of specialization that occurs when countries are engaged in trade. Baxter's result indicates the importance of explicitly 
considering investment decisions when capital goods exist. However, she does not consider heterogeneity in capital goods.

Accumulated empirical evidence shows that even in a narrowly defined industry, the quality (i.e., productivity and capital-intensity) of capital goods differs significantly across firms (Goolsbee, 2004; Foster et al., 2008). A large difference in capital goods presents even within firms (e.g., Goolsbee and Gross, 2000). ${ }^{1}$ Theoretically, a part of productivity difference is caused by the capacity constraint and the inflexibility (e.g., irreversibility) of capital goods (Cooper and Haltiwanger, 2006). Without capacity constraint, production occurs only for the most productive capital good. Besides, inflexibility is important. If capital goods could be instantaneously adjusted at no additional cost, firms would adjust the quality of capital goods according to their economic environment.

One source of heterogeneity in capital goods is vintage. New capital goods tend be more productive than older ones, thanks to technological progress. For example, using U.S. manufacturing plant data, Jensen et al. (2001) show that new entrants in recent years are significantly more productive than past entrants in their entry year. Another source of heterogeneity is idiosyncratic productivity variations among capital goods of the same vintage. For example, among the same make and model of equipment (industrial, mining, and farming machines, and office and transportation-related equipment), some machines malfunction, which requires a series of inspections and repairs, and effectively renders them less productive than other machines of the make and model. ${ }^{2}$ Since industrial machines such as assembly lines, supercomputers, transportation equipment and farm equipment, have become more and more complex and consist of many parts and/or computerized functions, a

\footnotetext{
${ }^{1}$ Goolsbee and Gross (2000) use data from airline companies. Obviously, capital goods (aircrafts) differ in their quality (e.g., capacity and fuel efficiency) even within the same airline company.

${ }^{2}$ Typical examples are transportation, construction and farm equipment (e.g., vehicles, dump tracks and combine harversters). This type of troubles is sufficiently common such that in the U.S., lemon laws (at the federal level, the Magnuson-Moss Warranty Act) protect consumers by ensuring appropriate recourse for compensation in the transaction of consumer vehicles and some other goods. However, the application of lemon laws for business vehicles is limited. For farming, a similar problem of new "lemon" machines is an important issue. Mechanical deficiencies lower the productivity of machines. Moreover, during the inspection and repairs, the machines cannot be operated, and hence effective productivity is much lower. The application of lemon laws to farming equipment depends on individual states.
} 
malfunction in one part of the machinery often leads to a breakdown of the entire machinery ("O-ring" theory: Kremer, 1993; Jones, 2011). Such variation leads to ex post productivity variations among ex ante same capital goods.

Putty-clay production technology is attractive for analyzing heterogeneity in capital goods since the approach incorporates vintage, capacity constraint, investment irreversibility, and endogenous utilization decision. Gilchrist and Williams (2000, 2005) introduce puttyclay technology into a closed-economy single-industry business cycle model. Capital goods (called "machines") have distinct vintage and idiosyncratic productivity. The machine-level labor-productivity depends on endogenously chosen capital-intensity and an exogenously determined idiosyncratic productivity component. This idiosyncratic productivity component is determined after the determination of capital-intensity. Once a machine is built, it is impossible to change its capital-intensity or to revert to investment goods. Moreover, capacity is constrained: the operational choice is to allocate one worker to each machine or to keep the machine idle. ${ }^{3}$

Under this heterogeneous capital setting, the aggregate production function in the steady state is represented as a standard Cobb-Douglas function, but its Solow residual is determined in part by the capital heterogeneity. With machine heterogeneity, less productive machines are not profitable, and hence not used in the equilibrium. Gilchrist and Williams (2005) show that a temporary increase in the idiosyncratic productivity variation provides an economywide productivity benefit through the optimal reallocation of variable factors, which is labor, across machines. That is, a change in the variance of idiosyncratic productivity component leads to a change in the aggregate productivity.

\footnotetext{
${ }^{3}$ Johansen (1972, chap. 9), Fuss (1977), Lasserre (1985) and Salvanes and Tveteras (2004) empirically confirm these key characterizations of putty-clay production technology using various micro-level data. In the context of the transportation, construction and farm equipment examples in Footnote 2, putty-clay works as follows. First, before installation or adoption, a firm can choose the size of, for example, dump tracks, but the size cannot be changed afterwards. The choice of the size determines capital-intensity because a dump track requires only one operator at a time. Some dump trucks experience a series of mechanical troubles ("lemons"), and possibly cannot be used. Productivity over a certain period of time becomes low or zero for these lemons. Production machines experiencing mechanical troubles also may produce products that do not meet quality standards. This also leads to low idiosyncratic productivity.
} 
Introducing this putty-clay technology into an international model considered by Baxter (1992), I find a novel source of comparative advantage: the heterogeneity of capital goods. In the steady-state of the dynamic " 2 by 2 by 2 " economy, trade pattern and gains from trade are generally described by Ricardian comparative advantage, as in Baxter (1992). Under autarky, differences in the magnitude of machine-level productivity heterogeneity across industries lead to differences in industry-level productivity. Larger machine-level variation provides an industry-level productivity benefit through the optimal allocation of labor across machines since less productive machines are not used in the equilibrium. Hence, an industry with larger idiosyncratic variation has higher industry-level productivity than an industry with less variation, and the price of the good is lower than the price of the other good. Moreover, in the industry-level aggregation, the production is represented as a Cobb-Douglas function, and the contribution of heterogeneity appears in a part of the Solow residual. By considering costless trade equilibrium, since the difference in the relative price under autarky determines the pattern of specialization, a country specializes in an industry with relatively larger capital goods heterogeneity. In this sense, trade is based on the technology-driven (i.e., Ricardian) comparative advantage, and the industry-level Solow residual is useful to predict trade pattern.

As an extension, I present the model with a fixed trade cost, and show that the model describes a situation in which the most productive (typically newer) machines export, moderately productive machines serve the domestic market, and the least productive (older) machines do not operate. This sorting implication is closely related to recent empirical literature findings (e.g., Bernard and Jensen, 1997, 1999; Bernard et al., 2003; Tomiura, 2007). While a popular explanation of this type of sorting developed by Melitz (2003) appeals to productivity heterogeneity, fixed costs of operation and exporting, and monopolistic competition, my model offers a fundamentally different mechanism of sorting based on the combination of productivity heterogeneity, fixed exporting cost, and capacity constraint. Essentially, since each machine faces capacity constraints, a machine is used for its most 
profitable operation. If the price of a good is higher in the foreign country, but delivering the good to the foreign country requires a fixed trade cost, exporting is profitable only for the most productive machines. Moreover, the model provides a prediction regarding the sorting and vintage. When technology is gradually improving and capital-embodied, a newer machine tends to be more productive and hence a newer machine is more likely to be used for exporting.

Even with the introduction of the fixed trade cost, the overall trade pattern is described as a Ricardian model. In general, a country produces more on the product with comparative advantage. The gains from trade are hence the combined and interactive results of the reallocation across industries (a reallocation that itself arises by exploiting comparative advantage), and reallocation across machines within an industry.

This paper offers new insights into three distinct research programs: (1) the source of comparative advantage, (2) firm-level trade, and (3) implications of putty-clay technology and micro-production based theories of aggregate productivity.

The source of comparative advantage has been the central subject of international trade studies (e.g., Feenstra, 2004). Traditionally, the comparative advantage results from a country's industry-level technology and aggregate factor endowment. ${ }^{4}$ Emerging literature considers differences in the distribution of skill across labor as a source of comparative advantage (Grossman and Maggi, 2000; Antràs et al., 2006; Bougheas and Riezman, 2007; Ohnsorge and Trefler, 2007). In particular, these studies underscore that a country with a concentrated skill distribution (e.g., Germany) has comparative advantage in an industry requiring many moderately skilled workers (e.g., precision machinery), while a country with sparse skill distribution (e.g., Italy) has a comparative advantage in an industry requiring a few outstanding experts (e.g., fashion design). While this logic is intuitive and appealing, another important aspect of heterogeneous distribution is selection mechanism, which my paper also emphasizes. Moreover, the distribution in my model is endogenously determined in the sense that

\footnotetext{
${ }^{4}$ Costinot (2009) organizes traditional theories of comparative advantage, and shows conditions of technology and factor endowment to emerge comparative advantages.
} 
capital-intensity is optimally chosen based on the knowledge of distribution of idiosyncratic productivity variation.

Second, my model adds a new view to micro-level trade literature. The sorting implication in my extended model is closely related to Melitz (2003), and an analysis regarding the gains from trade in this extended model resembles the way Bernard et al. (2007) applied Melitz (2003) to two industries. In the context of the sorting, the vast majority of the model is a version of Melitz (2003) in which monopolistic competition is an essential feature in addition to the underlying assumption, namely, the love of variety. ${ }^{5}$ A potential problem is that the assumption of the love of variety is too critical in the welfare analysis, and the literature attempts to organize the contribution of monopolistic competition and its parameterization to the welfare implications of firm-level trade models (c.f., Arkolakis et al., 2010, 2012; Behrens and Murata, 2011). An alternative view to sorting helps clarify the relationship between sorting in destination and gains from trade. In addition, my model offers several additional empirical predictions regarding the exporting status and vintage of capital goods: a firm with newer vintage machines is more likely to be an exporter; among exporters, export intensity is higher for the firm with newer vintage machines; and a firm starts exporting after an installation of new and productive machines. These predictions will be empirically pursued in future research.

Finally, the paper contributes to the literature of putty-clay technology and microproduction based theories of aggregate productivity. After Johansen (1959) introduced putty-clay technology, researchers intensively studied it from the 1960s to 80s mainly in the context of growth and investment models. ${ }^{6}$ The original idea is that in the aggregate production function, ex ante capital-intensity is freely chosen ("putty" or Cobb-Douglas function), but cannot be changed ex post ("clay" or Leontief function). Three papers from that era are closely related to my paper: Inada (1966) considers a two-sector Solow model

\footnotetext{
${ }^{5} \mathrm{~A}$ notable exception is a model by Bernard et al. (2003), who introduce Bertrand competition into a model of Eaton and Kortum (2002).

${ }^{6}$ See footnote 1 of Gilchrist and Williams (2000).
} 
with putty-clay technology; Grossman (1983), a trade application, considers the implications of a putty-clay production (without investment decision) to compare the specific-factor and Heckscher-Ohlin trade models; and Eaton (1979), another international application, examines the implication of exchange rate change on the allocation of factors. These classical papers assume exogenous investment decisions. A modern revival of putty-clay technology, with endogeneous investment decision, includes Atkeson and Kehoe (1999), Gilchrist and Williams (2000, 2004, 2005), Wei (2003), Birchenall (2004), Gourio (2011) and Choi and Rios-Rull (2012). In addition, the version of putty-clay in my paper, which relies on Gilchrist and Williams (2005), introduces heterogeneity in productivity across machines, and analyzes the industry-level productivity. This micro-founded analysis of aggregate productivity has its roots in a classical analysis by Houthakker (1955-56). ${ }^{7}$ These papers focus on implications of business cycle, labor market or asset price in dynamic single-industry closedeconomy settings. None of the recent papers features multi-industry and/or multi-country implications.

The rest of the paper is organized as follows. Section 2 is the main section of the paper, which first describes the investment decision problem, and then introduces this investment decision problem into a classical "2 by 2 by 2 " economy with endogenous capital accumulation and intertemporal decision. Section 3 is an extension of the baseline model, in which fixed trade cost is included, and shows the implication of the sorting in destination. Section 4 concludes.

\section{Model}

The heart of the model is the investment decision problem and its steady-state implications. The problem extends Gilchrist and Williams (2005) by including two industries. The investment decision involves an explicit dynamic stochastic problem, while the focus of the paper

\footnotetext{
${ }^{7}$ Related to Houthakker (1955-56) but distinct from studies based on putty-clay technology, Lagos (2006) also incorporates a Leontief micro-structure based on Houthakker (1955-56) with a search-and-matching model for explaining measured total factor productivity.
} 
is its steady-state. After describing the investment problem, I combine the problem into the "2 by 2 by 2 " economy with endogenous capital accumulation. Following the tradition of trade literature, I first consider a relative price of two goods under autarky, and then I analyze an open-economy equilibrium without trade cost. There are two countries, two final goods, and two factors of production. Final good $A$ is used just for consumption, while final good $B$ is used for both consumption and investment. Factors of production are capital and labor. Importantly, capital is endogenously accumulated. Time is discrete, and denoted by $t=0, \ldots, \infty$. Countries are indexed by subscript $i=1,2$, and industries are distinct by superscript $\iota=A, B$.

\subsection{Dynamic problem}

The investment decision model is stated with explicit treatment of uncertainty and dynamics. I first state the problem of the households, and then consider the investment problem.

\subsubsection{Households}

In each country $i$, there is a stand-in household. Households inelastically supply homogeneous labor $L_{i}{ }^{8}$ Households consume both good $A$ and $B$. Let $c_{i, t}^{\iota}$ denote consumption of goods $\iota$ in country $i$ at period $t$. The utility function is additively separable across time, and the period-utility is homothetic and identical across countries:

$$
E_{0} \sum_{t=0}^{\infty} \beta^{t} u\left(c_{i, t}^{A}, c_{i, t}^{B}\right),
$$

where $\beta$ is the subjective discount factor of the household. For simplicity of calculation, I use log-utility:

$$
u\left(c_{i, t}^{A}, c_{i, t}^{B}\right)=(1-\epsilon) \ln c_{i, t}^{A}+\epsilon \ln c_{i, t}^{B} .
$$

\footnotetext{
${ }^{8}$ Including a leisure-labor choice is straightforward, and it does not change any implications. See Appendix.
} 
The second good is used for consumption and investment. The intertemporal decision between period $t$ and $t+s$ is summarized by the ratio of the marginal utilities of the second goods at $t$ and $t+s$ (i.e., the "stochastic discount factor" in the macro-finance terminology):

$$
m_{i, t, t+s}=\beta^{s} \frac{\partial u_{i, t+s} / \partial c_{i, t+s}^{B}}{\partial u_{i, t} / \partial c_{i, t}^{B}} .
$$

\subsubsection{Investment problem}

Production takes place in a unit called "machine." In each period and for each industry, a set of investment opportunities to create new machines becomes available. Households determine capital-intensity of machines, and the number (quantity) of machines to be installed. At the time of investment, technology is constant-returns-to-scale, and the size of each machine is normalized to employ a maximum of one unit of labor. Once capital-intensity is determined, the investment is irreversible, and there is no substitutability between capital and labor.

Investment is subject to idiosyncratic variation in productivity. After the determination of the capital-intensity, the productivity is randomly drawn from a known log-normal distribution, which is industry- and country-specific. The productivity variation is a source of heterogeneity across machines within a vintage of capital goods. Each machine in a vintage is distinguished by an index $\xi$. The log-productivity of a machine $\xi$ of industry $\iota$ in country $i$ installed at period $t$ is:

$$
\ln \theta_{i, t}^{\iota}(\xi) \sim N\left(\ln \theta_{i, t}^{\iota}-0.5 \sigma_{i}^{\iota 2}, \sigma_{i}^{\iota 2}\right)
$$

The mean productivity is $E\left(\theta_{i}^{\iota}(\xi)\right)=\theta_{i, t}^{\iota}$ by the adjustment of $-0.5 \sigma_{i}^{\iota 2}$ of the log-normal distribution. Log-normal is empirically relevant (Campbell, 1998) and theoretically convenient (Gilchrist and Williams, 2000, 2005).

The capital-intensity of a newly installed machine is the same within an industry and a country, since the investment project is ex ante identical. By installing $k_{i, t}^{\iota}$ units of investment 
goods, the capital's contribution to labor-productivity is $k_{i, t}^{\iota}{ }^{\alpha}$. The parameter $\alpha \in(0,1)$ directly controls marginal product of capital. ${ }^{9}$ At period $t+s$, a machine installed at period $t$ (vintage $t$ ) can produce $y_{i, t+s}^{\iota}(\xi)$ units of goods $\iota$ if one unit of labor is assigned:

$$
y_{i, t+s}^{\iota}(\xi)=\theta_{i, t}^{\iota}(\xi) k_{i, t}^{\iota} \alpha l_{i, t+s}^{\iota}(\xi), \text { where } l_{i, t+s}^{\iota}(\xi) \in[0,1]
$$

If a machine is not used at a period, it remains idle at no cost.

Each period after the initial production (which takes place at $t+1$ ), machines have a constant probability $\delta$ of breaking down regardless of vintage, productivity, capital-intensity, industry or country.

The optimization problem at the time of capital-intensity decision $(t)$ is:

$$
\max _{k_{i, t}^{\iota},\left\{l_{i, t+s}^{\iota}(\xi) \in[0,1]\right\}_{s=1}^{\infty}}^{\infty}-p_{t}^{k} k_{i, t}^{\iota}+E_{t}\left[\sum_{s=1}^{\infty} m_{i, t, t+s}(1-\delta)^{s-1}\left(p_{i, t+s} \theta_{i, t}(\xi) k_{i, t}^{\iota}{ }^{\alpha}-w_{t+s}\right) l_{i, t+s}^{\iota}(\xi)\right]
$$

where $p_{i, t}^{k}$ is the price of the investment goods (which is $p_{i, t}^{B}$ under the current specification), $m_{i, t, t+s}$ is the stochastic discount factor, and the expectation operator $E_{t}$ takes over the time $t$ idiosyncratic productivity difference and all the other values at and after period $t+1$. The capital-intensity is chosen to maximize expected profits conditional on the known distribution but not on the realization of the idiosyncratic productivity. This optimization problem includes decisions about each of the different machines $(\xi)$, and directly solving the problem is difficult. However, the problem is simplified by introducing a variable summarizing a cut-off decision.

At period $t+s$, the revenue from operating a machine is $p_{i, t+s}^{\iota} \theta_{i, t}^{\iota}(\xi) k_{i, t}^{\iota}{ }^{\alpha}$, while the cost is $w_{i, t+s}$. By optimization, the decision follows a cut-off rule: one unit of labor is assigned if it is profitable $\left(p_{i, t+s}^{\iota} \theta_{i, t}^{\iota}(\xi) k_{i, t}^{\iota}{ }^{\alpha} \geq w_{i, t+s}\right)$, and no labor is assigned if it is not profitable. Let $f_{\Theta}$

\footnotetext{
${ }^{9}$ It is straightforward to make the share parameter $\alpha$ differs across industries, but the assumption of the common share parameter is useful to highlight the role of level and variance of productivity.
} 
denote the probability distribution function of $\theta_{i, t}^{\iota}(\xi)$. As shown in Appendix, the expected labor-use at period $t+s$ for a machine built at period $t$ is as:

$$
\begin{aligned}
& (1-\delta)^{s-1} \int_{\frac{w_{i, t+s}}{p_{i, t+s}^{\iota} k_{i, t}^{\iota}}}^{\infty} f_{\Theta}\left(\theta_{i, t}^{\iota}(\xi) \mid w_{i, t+s}, p_{i, t+s}^{\iota}, \theta_{i, t}^{\iota}\right) d \theta_{i, t}^{\iota}(\xi) \\
= & (1-\delta)^{s-1}\left(1-\Phi\left(z_{i, t, t+s}^{\iota}\right)\right),
\end{aligned}
$$

where $\Phi($.$) is the cumulative distribution function of the standard normal distribution, and$

$$
z_{i, t, t+s}^{\iota} \equiv \frac{1}{\sigma_{i}^{\iota}} \ln \left(\frac{w_{i, t+s}}{p_{i, t+s}^{\iota} \theta_{i, t}^{\iota} k_{i, t}^{\iota} \alpha}\right)+0.5 \sigma_{i}^{\iota} .
$$

Among machines built at period $t$, less productive machines are kept idle, while more productive machines are in operation. The variable $z_{i, t, t+s}^{\iota}$ summarizes the cutoff, which in general depends not only on the time $t+s$ but also the vintage $s$. As shown in Appendix, the expected output is also expressed by $\Phi($.$) as:$

$$
\begin{aligned}
& (1-\delta)^{s-1}\left(\int_{\frac{w_{i, t+s}}{p_{i, t+s}^{\iota} k_{i, t}^{\iota}}}^{\infty} \theta_{i, t}^{\iota}(\xi) k_{i, t}^{\iota}{ }^{\alpha} f_{\Theta}\left(\theta_{i, t}^{\iota}(\xi) \mid w_{i, t+s}, p_{i, t+s}^{\iota}, \theta_{i, t}^{\iota}\right) d \theta_{i, t}^{\iota}(\xi)\right) \\
= & (1-\delta)^{s-1}\left(1-\Phi\left(z_{i, t, t+s}^{\iota}-\sigma_{i}^{\iota}\right)\right) \theta_{i, t}^{\iota} k_{i, t}^{\iota \alpha} .
\end{aligned}
$$

The term $1-\Phi\left(z_{i, t, t+s}^{\iota}-\sigma_{i}^{\iota}\right)$ is a capacity utilization rate, i.e., the ratio of output produced from the capital goods installed at $t$ to the level of maximum output using the capital goods. ${ }^{10}$ Using (7) and (9), at period $t+s$ the expected net income of a surviving machine build at $t$ is as:

$$
p_{i, t+s}^{\iota}\left(1-\Phi\left(z_{i, t, t+s}^{\iota}-\sigma_{i}^{\iota}\right)\right) \theta_{i, t}^{\iota} k_{i, t}^{\iota}{ }^{\alpha}-w_{i, t+s}\left(1-\Phi\left(z_{i, t, t+s}^{\iota}\right)\right) .
$$

\footnotetext{
${ }^{10}$ The inside of $\Phi($.$) is z-\sigma$, not $z$. This adjustment comes from the use of truncated expectation formula.
} 
The first derivative of this equation with respect to $z_{i, t, t+s}^{\iota}$ is:

$$
0=-p_{i, t+s}^{\iota} \phi\left(z_{i, t, t+s}^{\iota}-\sigma_{i}^{\iota}\right) \theta_{i, t}^{\iota} k_{i, t}^{\iota \alpha}+w_{i, t+s} \phi\left(z_{i, t, t+s}^{\iota}\right)
$$

where $\phi($.$) is the probability density function of the standard normal distribution. Using the$ functional form of $\phi($.$) , a rearrangement of this expression (11) leads to equation (8). This$ means that the capital-intensity decision problem (6) involving a machine-level problem can be rewritten in an industry-level problem using $z_{i, t, t+s}$ as an additional variable:

$$
\begin{aligned}
\max _{k_{i, t}^{\iota},\left\{z_{i, t, t+s}^{\iota}\right\}_{s=1}^{\infty}} & -p_{i, t}^{k} k_{i, t}^{\iota}+E_{t}\left[\sum_{s=1}^{\infty} m_{i, t, t+s}(1-\delta)^{s-1}\right. \\
& \left.\times\left(p_{i, t+s}^{\iota}\left(1-\Phi\left(z_{i, t, t+s}^{\iota}-\sigma_{i}^{\iota}\right)\right) \theta_{i, t}^{\iota} k_{i, t}^{\iota}{ }^{\alpha}-w_{i, t+s}\left(1-\Phi\left(z_{i, t, t+s}^{\iota}\right)\right)\right)\right] .
\end{aligned}
$$

The first order condition with respect to $z_{i, t, t+s}^{\iota}$ is (11), or equivalently, (8). Depending on the prices, $k_{i, t}^{\iota}$ could be zero. When the investment is positive, the first order condition is the first derivative with respect to $k_{i, t}^{\iota},{ }^{11}$ and hence:

$$
0=-p_{i, t}^{k}+\alpha E_{t}\left[\sum_{s=1}^{\infty} m_{i, t, t+s}(1-\delta)^{s-1} p_{i, t+s}^{\iota}\left(1-\Phi\left(z_{i, t, t+s}^{\iota}-\sigma_{i}^{\iota}\right)\right) \theta_{i, t}^{\iota} k_{i, t}^{\iota \alpha-1}\right]
$$

Once a machine is installed, each machine earns positive profits if it operates. An equilibrium requires expected profits to be zero. Such a condition, a free-entry, implies that:

$$
\begin{aligned}
p_{i, t}^{k} k_{i, t}^{\iota}= & E_{t}\left[\sum_{s=1}^{\infty} m_{i, t, t+s}(1-\delta)^{s-1}\right. \\
& \left.\times\left(p_{i, t+s}^{\iota}\left(1-\Phi\left(z_{i, t, t+s}^{\iota}-\sigma_{i}^{\iota}\right)\right) \theta_{i, t}^{\iota} k_{i, t}^{\iota}{ }^{\alpha}-w_{i, t+s}\left(1-\Phi\left(z_{i, t, t+s}^{\iota}\right)\right)\right)\right] .
\end{aligned}
$$

This free-entry condition, together with the resource constraints presented below, determines the total number of newly installed machines in each industry, $q_{i, t}^{\iota}$.

\footnotetext{
${ }^{11}$ Precisely, a change in $k_{i, t}^{\iota}$ changes future decisions of $z_{i, t, t+s}^{\iota}$. By the envelope condition (11), this indirect effect does not appear in (13).
} 


\subsubsection{Industry aggregation}

Total labor-use in the industry $\iota$ is the sum of labor requirements of all existing machines:

$$
l_{i, t}^{\iota}=\sum_{s=1}^{\infty}(1-\delta)^{s-1}\left(1-\Phi\left(z_{i, t-s, t}^{\iota}\right)\right) q_{i, t-s}^{\iota}
$$

and the total production of industry $\iota$ is:

$$
y_{i, t}^{\iota}=\sum_{s=1}^{\infty}(1-\delta)^{s-1}\left(1-\Phi\left(z_{i, t-s, t}^{\iota}-\sigma_{i}^{\iota}\right)\right) \theta_{i, t-s}^{\iota} k_{i, t-s}^{\iota}{ }^{\alpha} q_{i, t-s}^{\iota} .
$$

The total gross investment for industry $\iota$ at period $t$ is the product of the number of machines and their capital-intensity, $k_{i, t}^{\iota} q_{i, t}^{\iota}$. In each period, $\delta$ fraction of capital goods is exogenously broken. If a researcher uses a standard perpetual inventory method to calculate capital stock of industry $\iota$, the calculated industry-level capital stock $K_{i, t}^{\iota}$ follows the usual transition expression:

$$
K_{i, t+1}^{\iota}=(1-\delta) K_{i, t}^{\iota}+k_{i, t}^{\iota} q_{i, t}^{\iota}
$$

\subsubsection{Resource constraints and other conditions}

The first goods are pure consumption goods, while the second goods are consumption and investment goods. The resource constraints are:

$$
\begin{aligned}
\sum_{i=1}^{N} y_{i, t}^{A} & =\sum_{i=1}^{N} c_{i, t}^{A}, \\
\sum_{i=1}^{N} y_{i, t}^{B} & =\sum_{i=1}^{N}\left(c_{i, t}^{B}+k_{i, t}^{A} q_{i, t}^{A}+k_{i, t}^{B} q_{i, t}^{B}\right), \\
l_{i, t}^{A}+l_{i, t}^{B} & =L_{i, t} .
\end{aligned}
$$

There is one country $(N=1)$ under autarky, and two $(N=1,2)$ under costless trade. Since the second goods are used as investment goods, the price of the investment goods is that of 
the second goods:

$$
p_{i, t}^{k}=p_{i, t}^{B}
$$

Under costless trade, $p_{t}^{\iota}=p_{1, t}^{\iota}=p_{2, t}^{\iota}$. I also impose a period-by-period trade balance:

$$
p_{t}^{A}\left(y_{i t}^{A}-c_{i t}^{A}\right)+p_{t}^{B}\left(y_{i t}^{B}-c_{i t}^{B}-k_{i t}^{A} q_{i t}^{A}-k_{i t}^{B} q_{i t}^{B}\right)=0 .
$$

A competitive equilibrium of the economy is defined as usual: sequences of prices and quantities that are consistent with the household's optimization, the investment decision, the resource constraints, and conditions on prices. For costless trade equilibrium, the trade balance is also required.

\subsection{Steady-state implications of zero-growth economy}

In the rest of the paper, the analysis focuses on the steady-state/balanced-growth equilibrium in which all the variables stay constant, and the distribution of machines is stationary. In particular, the analysis starts from a case without trend growth. The mean productivity is constant over time $E\left(\theta_{i}^{\iota}(\xi)\right)=\theta_{i, t}^{\iota}=\theta_{i}^{\iota}$. Under this assumption, I can show many results analytically.

\subsubsection{The investment problem}

The variables in the steady-state are expressed without time subscripts, for example, $k_{i t}^{\iota}=k_{i}^{\iota}$. The stochastic discount factor $m_{i, t, t+s}$ defined by (3) is replaced by $\beta^{s}$. Let $R$ denote the steady-state user cost:

$$
R=\frac{1}{\beta}-1+\delta
$$


The variable of the cut-off decision in general depends both on time and vintage. In the steady-state, the right-hand-side of (8) depends on neither, and hence $z_{i}^{\iota}$ is constant within industry and country. The utilization decision condition (11) is as:

$$
0=-p_{i}^{\iota} \phi\left(z_{i}^{\iota}-\sigma^{\iota}\right) \theta_{i}^{\iota} k_{i}^{\iota \alpha}+w_{i} \phi\left(z_{i}^{\iota}\right)
$$

Similarly, equations (13) and (14) are as:

$$
\begin{aligned}
& p_{i}^{k} k_{i}^{\iota}=\frac{\alpha}{R} p_{i}^{\iota}\left(1-\Phi\left(z_{i}^{\iota}-\sigma_{i}^{\iota}\right)\right) \theta_{i}^{\iota} k_{i}^{\iota \alpha}, \\
& p_{i}^{k} k_{i}^{\iota}=\frac{\alpha}{1-\alpha} \frac{1}{R} w\left(1-\Phi\left(z_{i}^{\iota}\right)\right) .
\end{aligned}
$$

Combining (24), (25) and (26) leads to the following equation, which pins down $z_{i}^{\iota}$ :

$$
1-\alpha=\frac{\phi\left(z_{i}^{\iota}-\sigma_{i}^{\iota}\right) /\left(1-\Phi\left(z_{i}^{\iota}-\sigma_{i}^{\iota}\right)\right)}{\phi\left(z_{i}^{\iota}\right) /\left(1-\Phi\left(z_{i}^{\iota}\right)\right)}
$$

Lemma 1. Equation (27) has a unique solution, and $d z_{i}^{\iota} / d \sigma_{i}^{\iota}>1$. (Gilchrist and Williams, 2005)

The proof is given by Gilchrist and Williams (2005). ${ }^{12}$ Lemma 1 implies that $z_{i}^{\iota}$ depends only on $\alpha$ and $\sigma_{i}^{\iota}$. It does not depend on the mean productivity $\theta_{i}^{\iota}$, the real wage $w_{i}$, or the prices of the good $p_{i}^{\iota}$ and investment goods $p_{i}^{k}$. Since Gilchrist and Williams (2005) analyze a single-industry economy, the finding that $z_{i}^{\iota}$ does not depend on the prices is not surprising. However, equation (27) shows that even with a two-industry extension, the steady-state operation decision does not depend on the prices.

\footnotetext{
${ }^{12}$ The basic idea of the proof is to calculate the upper limit (which is unity) and lower limit (which is zero) of the right-hand-side, and to show monotonicity of the right-hand-side with respect to $z$. The sign of the derivative is determined by the implicit function theorem.
} 
The aggregation equations (15) and (16) are as:

$$
\begin{aligned}
l_{i}^{\iota} & =\frac{1}{\delta}\left(1-\Phi\left(z_{i}^{\iota}\right)\right) q_{i}^{\iota}, \\
y_{i}^{\iota} & =\frac{1}{\delta}\left(1-\Phi\left(z_{i}^{\iota}-\sigma_{i}^{\iota}\right)\right) \theta_{i}^{\iota} k_{i}^{\iota \alpha} q_{i}^{\iota} .
\end{aligned}
$$

By combining (25), (26), (28), and (29):

$$
(1-\alpha) p_{i}^{\iota} y_{i}^{\iota}=w_{i} l_{i}^{\iota}
$$

that is, labor's income share is constant. This condition motivates Cobb and Douglas (1928) to discover the famous functional form. Hence, in the steady-state, this putty-clay microstructure is observationally consistent with industry-level Cobb-Douglas technology.

Moreover, from (17), the implied industry capital stock is as:

$$
K_{i}^{\iota}=\frac{1}{\delta} k_{i}^{\iota} q_{i}^{\iota}
$$

and combining this with (28) and (29) leads to an expression of the industry-level production function as:

$$
\begin{aligned}
y_{i}^{\iota} & =\frac{1}{\delta}\left(1-\Phi\left(z_{i}^{\iota}-\sigma_{i}^{\iota}\right)\right) \theta_{i}^{\iota} k_{i}^{\iota \alpha} q_{i}^{\iota} \\
& =\frac{1}{\delta}\left(1-\Phi\left(z_{i}^{\iota}-\sigma_{i}^{\iota}\right)\right) \theta_{i}^{\iota} k_{i}^{\iota \alpha}\left(l_{i}^{\iota} \delta\left(1-\Phi\left(z_{i}^{\iota}\right)\right)^{-1}\right)^{1-\alpha} q_{i}^{\iota \alpha} \\
& =\theta_{i}^{\iota} \frac{1-\Phi\left(z_{i}^{\iota}-\sigma_{i}^{\iota}\right)}{\left(1-\Phi\left(z_{i}^{\iota}\right)\right)^{1-\alpha}} K_{i}^{\iota \alpha} l_{i}^{\iota 1-\alpha} .
\end{aligned}
$$

In the steady-state the industry-level aggregate production function is exactly Cobb-Douglas form. Its Solow residual has two components: the part coming from the mean productivity, and the part coming from the magnitude of heterogeneity. ${ }^{13}$ A straightforward calculation

\footnotetext{
${ }^{13}$ This aggregate representation of Cobb-Douglas production function based on the putty-clay microstructure is available in the steady-state of a single-good setting. Gilchrist and Williams (2000, 2005) do not explicitly present this representation, although they study the effect of a short-run change in $\sigma$ on the
} 
shows that the Solow residual is increasing in $\sigma_{i}^{\iota}$.

Lemma 2. The Solow residual in the steady-state is increasing in the parameter $\sigma_{i}^{\iota}$.

Proof. For notational simplicity, both superscripts and subscripts are dropped. By taking the first derivative:

$$
\begin{aligned}
\frac{\partial \text { Solow }}{\partial \sigma} & =\theta\left(\frac{-\phi(z-\sigma)}{(1-\Phi(z))^{1-\alpha}}\left(\frac{d z}{d \sigma}-1\right)+(1-\alpha) \frac{1-\Phi(z-\sigma)}{\left.(1-\Phi(z))^{2-\alpha} \phi(z) \frac{d z}{d \sigma}\right)}\right. \\
& =\theta \frac{1-\Phi(z-\sigma)}{(1-\Phi(z))^{1-\alpha}}\left(\frac{-\phi(z-\sigma)}{(1-\Phi(z-\sigma))}\left(\frac{d z}{d \sigma}-1\right)+(1-\alpha) \frac{\phi(z)}{(1-\Phi(z))} \frac{d z}{d \sigma}\right) \\
& =\theta \frac{1-\Phi(z-\sigma)}{(1-\Phi(z))^{1-\alpha}}\left(\frac{-\phi(z-\sigma)}{(1-\Phi(z-\sigma))}\left(\frac{d z}{d \sigma}-1\right)+\frac{\phi(z-\sigma)}{(1-\Phi(z-\sigma))} \frac{d z}{d \sigma}\right) \\
& =\theta \frac{\phi(z-\sigma)}{(1-\Phi(z))^{1-\alpha}} .
\end{aligned}
$$

From the second to third line, equation (27) is used. Since all the terms in the last line are positive, the first derivative is positive.

The intuition behind this result is that large heterogeneity in productivity across machines provides an industry-wide productivity benefit through the optimal allocation of labor across machines. In this model, less productive machines are not used. Large $\sigma$ means that the distribution of machines (with respect to labor-productivity) is flat; there are many highly productive machines and many unproductive machines. The unproductive machines are not sufficiently profitable to cover the operational cost (wage), so they are kept idle. The industry-level productivity is high since the production mainly takes place with productive machines. On the contrary, small $\sigma$ means the productivity distribution is concentrated; there are many "so-so" productive machines. Most of the machines are in operation, and the industry-wide productivity gain through the selection is small. In an extreme case, if all machines are the same, the industry-level productivity is the same as that of the individual machines. The industry has no productivity gains from the selection.

aggregate productivity. 
The role of the selection in determining industry-level productivity becomes clear by considering the capacity utilization rate. As shown in (9) the term $1-\Phi(z-\sigma)$ is the capacity utilization rate of the industry. Note that $\Phi($.$) is a monotonically increasing function$ because it is the cumulative distribution function of the standard normal distribution. Since $d z / d \sigma>1$ (by Lemma 1 ) and $\Phi($.$) is monotonically increasing, the capacity utilization rate$ $1-\Phi(z-\sigma)$ is monotonically decreasing in $\sigma$. In other words, the more productivity varies, the more severe the selection. Together with the previous result,

Lemma 3. In the steady-state there is a one-to-one relationship between the capacity utilization rate $1-\Phi\left(z_{i}^{\iota}-\sigma_{i}^{\iota}\right)$ and the parameter $\sigma_{i}^{\iota}$. The Solow residual is larger if the capacity utilization rate is lower.

The statement appears to contradict a standard short-run argument that the productivity (calculated without adjusting capacity utilization rate) is high if the capacity utilization rate is high (e.g., Greenwood et al., 1988). The statement here is about the steady-state with heterogeneous capital goods. Productivity is high if the steady-state capacity utilization rate is low, because a low capacity utilization results from a severe selection.

In summary, a difference in the productivity across capital goods is a source of the industry-level productivity through the selection.

\subsubsection{Autarky}

I first consider the implications of the putty-clay technology under autarky. For notational simplicity, country subscript $i$ will be dropped. The focus is the relative price of two industries $p^{B} / p^{A}$. From equations $(25)$ and $(26)$, the relative price is:

$$
\frac{p^{B}}{p^{A}}=\frac{\theta^{A}}{\theta^{B}} \frac{\frac{1-\Phi\left(z^{A}-\sigma^{A}\right)}{\left(1-\Phi\left(z^{A}\right)\right)^{1-\alpha}}}{\frac{1-\Phi\left(z^{B}-\sigma^{B}\right)}{\left(1-\Phi\left(z^{B}\right)\right)^{1-\alpha}}}
$$

The relative price is the inverse of the ratio of the Solow residuals. If $\sigma^{A}=\sigma^{B}$ and $\theta^{A}=\theta^{B}$, then $z^{A}=z^{B}$ and the relative price is 1 . If $\sigma^{A}=\sigma^{B}$ but $\theta^{A} \neq \theta^{B}$, then the relative price 
depends only on the mean productivities, as in the classical Ricardian model. If $\sigma^{A} \neq \sigma^{B}$, since the Solow residual is increasing in $\sigma$,

Proposition 1. Under autarky, the relative price $p^{B} / p^{A}$ depends only on the capital share parameter $\alpha$, the levels $\theta^{\iota}$ and variations $\sigma^{\iota}$ of productivities. It does not depend on the demand conditions. The relative price $p^{B} / p^{A}$ is monotonically increasing in $\sigma^{A}$, and monotonically decreasing in $\sigma^{B}$.

Under autarky, the relative price is determined by technology. Intuitively, since the amount of capital is adjustable, and is determined by the user cost, labor is effectively the only input used to determine the relative supply. However, labor is homogeneous, and hence wage is adjusted to be consistent with relative technology. Consequently, the relative price is purely determined by technology. This logic is the same as that used for an economy with the neoclassical production technology (Baxter, 1992).

Adding to the mean productivity, the variance plays a role in the putty-clay setting. This effect occurs because, contrary to standard neoclassical production function, productivity is heterogeneous across machines. Less productive machines are not used since they are not profitable. Due to this industry-level selection, productivity is higher if the distribution is flatter. The parameter $\sigma^{\iota}$ determines the variability of productivity distribution, and hence the relative price is lower for a sector with higher $\sigma^{\iota}$.

In this model, however, not just exogenous distribution but also endogenous investment plays an important role in determining labor productivity. In particular, under autarky, capital-intensity decision actually attenuates the selection mechanism. A rearrangement of (26) leads to:

$$
\frac{k^{B}}{k^{A}}=\frac{1-\Phi\left(z^{B}\right)}{1-\Phi\left(z^{A}\right)} .
$$

It is straightforward to obtain the first derivative with respect to $\sigma^{\iota}$, for example, with respect 
to $\sigma^{B}$ :

$$
\frac{d \frac{k^{B}}{k^{A}}}{d \sigma^{B}}=\frac{-\phi\left(z^{B}\right)}{1-\Phi\left(z^{A}\right)} \frac{d z^{B}}{d \sigma^{B}}<0 .
$$

An industry with higher variation has lower capital-intensity. The difference in the laborproductivities across industries is not as large as the difference in the exogenous productivity component because in this model the labor-productivity is the product of the underlying idiosyncratic productivity $\theta_{i}^{\iota}(\xi)$ and the capital-intensity term $k_{i}^{\iota \alpha}$. The endogenous nature of a capital-intensity decision decreases the difference between labor-productivities across industries. In the industry with large $\sigma$ a machine with low labor-productivity will not be used and hence it is "risky" to make a large capital-intensity investment for an individual machine. Instead, investment is made mainly in increasing the number of machines $\left(q^{\iota}\right)$. On contrary, in the industry with $\sigma$, most of the machines will be used, so that investment is directed toward developing the labor-productivity of each machine.

The capital-intensity of each machine $k^{\iota}$ is not the same as the industry-level capital-labor ratio $K^{\iota} / l^{\iota}$. From equations (26), (28), and (31):

$$
\frac{K^{\iota}}{l^{\iota}}=\frac{\frac{1}{\delta} k^{\iota} q^{\iota}}{l^{\iota}}=\frac{\alpha}{1-\alpha} \frac{w}{R} \frac{1}{p^{k}} .
$$

The right-hand-side does not depend on industry $\iota$, and hence industry-level capital-labor ratios are the same across industries. The relative capital-labor ratio is not correlated with the relative price. Accordingly, the industry-level capital-labor ratio does not contain any useful information for predicting the comparative advantage. The important variable is technology.

\subsubsection{Two-country equilibrium without trade cost}

Given the autarky relative price, it is straightforward to determine the pattern of specialization when two countries are engaged in costless trade. Two countries (country 1 and 2) are 
distinguished by subscript $i=1,2$. Without trade cost, the price must be equalized across countries and hence $p_{i}^{A}=p^{A}$ and $p_{i}^{B}=p^{B}$. Suppose that country 2 possesses comparative advantage in producing good $B$, i.e., $p_{2}^{B} / p_{2}^{A}<p_{1}^{B} / p_{1}^{A}$. Country 2 then tends to specialize in good $B$ productions. If the price is so low (due to cheaper imported goods), then even very productive machines of industry $A$ in country 2 would earn negative profits. ${ }^{14}$ In this case, the industry-level investment, labor and output are zero: $y_{2}^{A}=k_{2}^{A}=q_{2}^{A}=l_{2}^{A}=0$, that is, country 2 completely specializes.

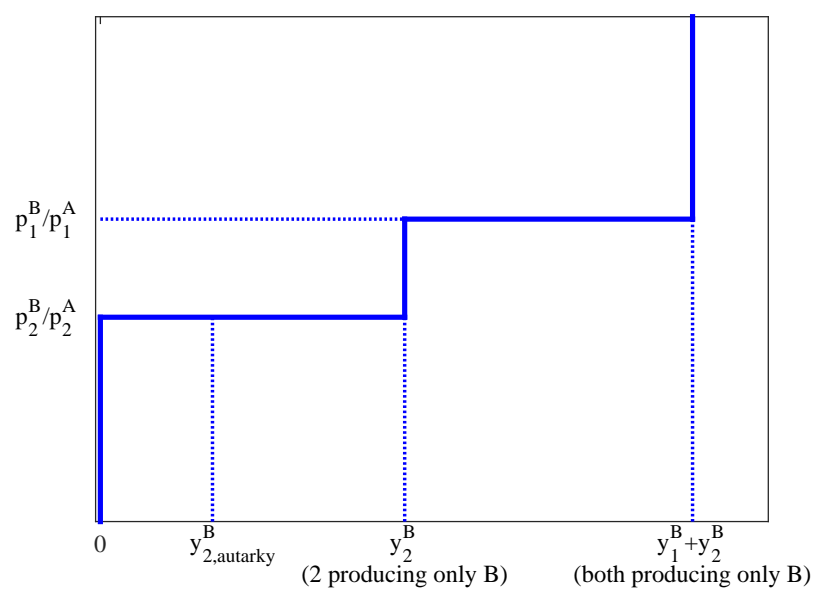

Figure 1: World supply of good $B$

Given this structure, the rest of the equilibrium properties are parallel to the textbook Ricardian model (e.g., Feenstra, 2004, Chapter 1). The relative price depends on the demandside. Figure 1 illustrates the world supply of good $B$, which is a typical "stair-step" pattern. The vertical axis is the relative price. If the world relative price, $p^{B} / p^{A}$, turns out to be smaller than the autarky relative price in country 2 , both countries are fully specialized in production of good $A$, and supply of good $B$ is zero. If the relative price with trade is the same as the autarky relative price in country 2 , then country 2 produces both goods, while country 1 completely specializes in the production of good $A$. Instead, if the relative price is larger than the autarky relative price in country 1 , both countries produce good $B$. If the world relative price is in-between, country 1 specializes in good $A$ and country 2 specializes

\footnotetext{
${ }^{14}$ Formally, for given prices (26) satisfies only if $k_{i}^{\iota}=0$. See Appendix for details.
} 
good $B$, and as shown in the Appendix, the relative price is given by:

$$
\frac{p^{B}}{p^{A}}=\left(\frac{\epsilon+\frac{\alpha \delta}{R-\alpha \delta}}{1-\epsilon}\right)^{1-\alpha} \frac{\theta_{1}^{A}}{\theta_{2}^{B}} \frac{\frac{1-\Phi\left(z_{1}^{A}-\sigma_{1}^{A}\right)}{\left(1-\Phi\left(z_{1}^{A}\right)\right)^{1-\alpha}}}{\frac{1-\Phi\left(z_{2}^{B}-\sigma_{2}^{B}\right)}{\left(1-\Phi\left(z_{2}^{B}\right)\right)^{1-\alpha}}}
$$

The results are summarized as:

Proposition 2. The world supply curve in the steady-state has a "stair-step" pattern. The relative price under the complete specialization is determined by three different terms that individually capture (1) demand condition, (2) mean productivities of the distributions, and (3) relative dispersions of the productivities.

Other properties are also Ricardian. For example, trade improves welfare for both countries, although, in general, the wages are not equalized across countries. In this model, welfare is precisely calculated by the household utility. In the Appendix, I show that (1) trade is welfare improving for both countries, and (2) the wage difference across countries captures the difference in the utility. Moreover, under the complete specialization, the wage difference across countries depends on demand for two goods.

\subsubsection{Comparison}

The model resembles the standard " 2 by 2 by 1 " Ricardian trade model, and the " 2 by 2 by 2" economy with endogenous capital accumulation model of Baxter (1992).

If the production of each industry is given by a linear-in-labor technology, the model is identical to the textbook "2 by 2 by 1" Ricardian trade model (e.g., Feenstra, 2004). In particular, suppose that the industry-level production function is as:

$$
y_{i}^{\iota}=\theta_{i}^{\iota} l_{i}^{\iota}
$$

then the model is that of the classical Ricardian model. ${ }^{15}$ In this case, the relative price

\footnotetext{
${ }^{15}$ Notice that I follow macro-tradition in that the productivity $\theta_{i}^{\iota}$ expresses marginal product of labor
} 
under the complete specialization is as:

$$
\frac{p^{B}}{p^{A}}=\frac{\epsilon}{1-\epsilon} \frac{\theta_{1}^{A}}{\theta_{2}^{B}}
$$

The first term captures the demand condition, while the second term captures the supply condition. In the classical Ricardian model, capital accumulation is abstracted so that there is no demand associated with investment. The demand is entirely determined by consumption share parameter in the utility function, $\epsilon$.

The second term captures the effect of technological difference. If $\theta_{1}^{A}$ is much higher than $\theta_{2}^{B}$, then it is less costly to produce good $A$ than $\operatorname{good} B$, so that the world price of good $A$ is lower than the world price of good $B$.

If the industry-level production technology is as:

$$
y_{i}^{\iota}=\theta_{i}^{\iota} K_{i}^{\iota \alpha} l_{i}^{\iota 1-\alpha}
$$

where $K_{i}^{\iota}$ is total capital stock in the industry, and capital accumulation follows the standard law of motion:

$$
K_{i, t+1}^{\iota}=(1-\delta) K_{i, t}^{\iota}+\text { investment }_{i, t}^{\iota}
$$

then, this is a case analyzed by Baxter (1992), and the relative price under complete specialization is as:

$$
\frac{p^{B}}{p^{A}}=\left(\frac{\epsilon+\frac{\alpha \delta}{R-\alpha \delta}}{1-\epsilon}\right)^{1-\alpha} \frac{\theta_{1}^{A}}{\theta_{2}^{B}} .
$$

The first term again captures the effect of the demand, while the second term captures the technology. Contrary to the classical Ricardian model, the demand term reflects not only consumption demand but also the demand coming from investment motive, which is $\alpha \delta /(R-$ rather than the marginal labor requirement as is common in trade literature. 
$\alpha \delta$ ). The second term, capturing the technology, is the same as the classical Ricardian model. This is the finding by Baxter (1992), that is, since the capital is endogenously determined, technology, not the endowment, is the determinant of the comparative advantage and the relative price under costless trade equilibrium.

Table 1: Comparison of the models

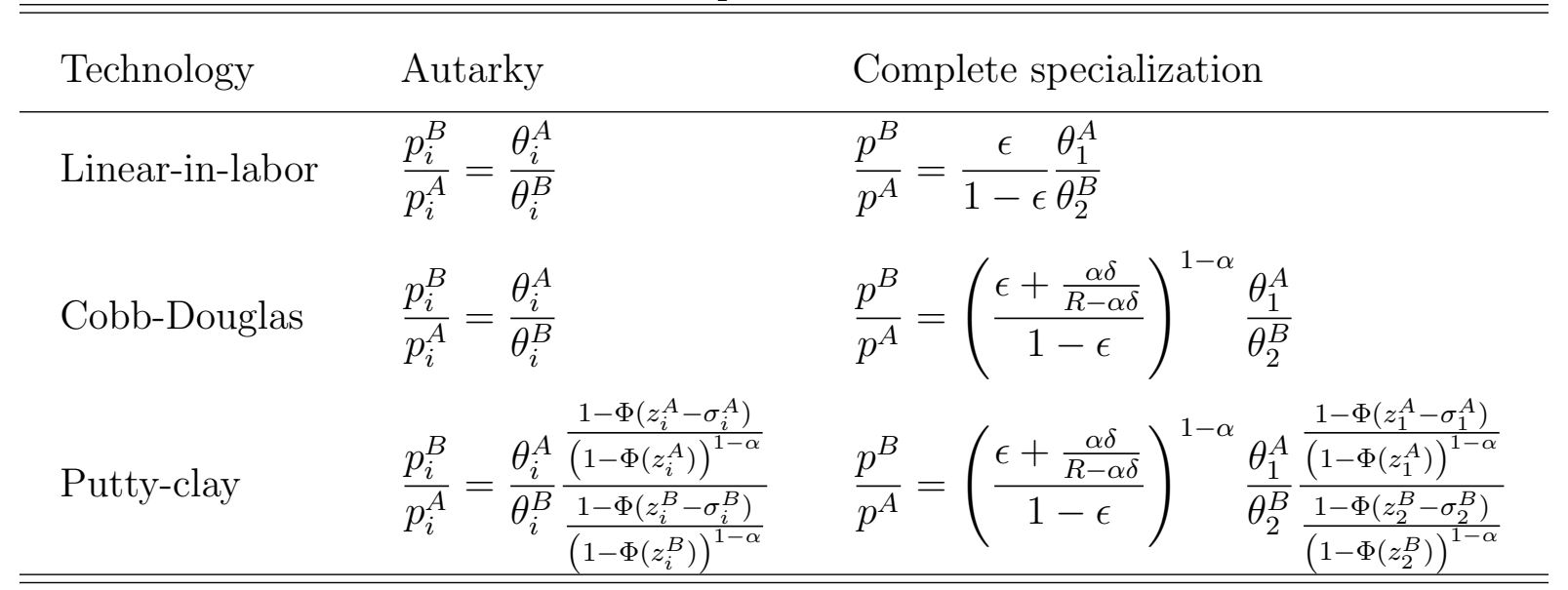

Notes: $i=1,2$ is country, $\iota=A, B$ is industry, $\epsilon$ is consumption share of good $\mathrm{B}$ in the period-utility, $R=1 / \beta-1+\delta, \beta$ is subjective discount factor, $\delta$ is depreciation rate, $\alpha$ is capital's share in the production function, and $z$ is utilization rate (see equation (27)). Complete specialization is a case in which country 1 specializes in production of good $A$, and country 2 specializes in production of good $B$.

The relative price under costless trade of the putty-clay model is (37), and Table 1 compares these three models. As is clear from Table 1, the implication of these models is Ricardian. The pattern of comparative advantage is determined by the relative price under autarky, and it is fully captured by the industry-level Solow residuals. In the case of the putty-clay technology, not only the mean level of productivity $(\theta)$ but also the magnitude of the heterogeneity $(\sigma)$ contributes to the measured Solow residual.

The relative price under costless trade with perfect specialization is determined by both demand and supply conditions. When we compare the linear-in-labor and Cobb-Douglas production technologies, the difference is driven by the presence of investment. In the case of the Cobb-Douglas production technology, technology is homogeneous within country and industry. The mean productivities are the key indicators capturing the autarky relative price and the pattern of trade. In the case of the putty-clay technology, selection across 
heterogeneous capital goods additionally affects supply.

\subsection{The balanced growth economy}

By including capital-embodied technological progress, the model provides additional predictions regarding productivity variation, industry-level productivity, and the vintage of capital goods. Suppose that technology is improving, and it is embodied in the capital goods; specifically, the mean productivity has a common trend growth, $E\left(\theta_{i}^{\iota}(\xi)\right)=\theta_{i, t}^{\iota}=(1+g)^{t(1-\alpha)} \theta_{i}^{\iota}$. Let variables without time subscripts denote their values on the balanced growth path. The analysis in Section 2.2 is a special case in which $g=0$. When $g>0$, the calculations are not as simple as in the case of $g=0$. In particular, with trend growth of technology, an old machine is generally less productive than a new machine. Accordingly, the cutoff depends on the vintage of the capital. Since newer machines are in general more productive than older machines, the ratio of operation of an " $s+1$ periods old" machine is lower than that of an "s periods old" machine.

The cutoff variable $z_{i s}^{\iota}$ depends on the vintage of the machine:

$$
z_{i, s}^{\iota}=\frac{1}{\sigma_{i}^{\iota}} \ln \left(\frac{w_{i}}{p_{i}^{\iota} \theta_{i}^{\iota} k_{i}^{\iota \alpha}}\right)+0.5 \sigma_{i}^{\iota}+\frac{s}{\sigma_{i}^{\iota}} \ln (1+g)
$$

Since $g>0, z_{i, s+1}>z_{i, s}$. A higher $z$ means a larger fraction of machines is below the operational cutoff.

As shown in the Appendix, the condition corresponding to (27) for $g>0$ involves $z_{i, s}^{\iota}$ for $s=1,2, \ldots$ Gilchrist and Williams (2005) show that even when $g>0$, the existence of $z_{i, s}^{\iota}$ is always ensured. Moreover, they show that under a mild condition $z_{i, s}^{\iota}$ is uniquely determined.

Once $z_{i, s}^{\iota}$ is determined, the industry-level output can be expressed as a generalized 
version of $(32)$ :

$$
y_{i}^{\iota}=\theta_{i}^{\iota}(g+\delta)^{\alpha} \frac{\left(\sum_{s=1}^{\infty}(1+g)^{-s}(1-\delta)^{s-1}\left(1-\Phi\left(z_{i, s}^{\iota}-\sigma_{i}^{\iota}\right)\right)\right)}{\left(\sum_{s=1}^{\infty}(1-\delta)^{s-1}\left(1-\Phi\left(z_{i, s}^{\iota}\right)\right)\right)^{1-\alpha}} K_{i}^{\iota \alpha} l_{i}^{\iota 1-\alpha}
$$

Since $z_{i, s}^{\iota}$ depends on $\sigma_{i}^{\iota}$, the Solow residual depends on $\sigma_{i}^{\iota}$.

Figure 2 illustrates the relationship between $\sigma$, vintage, and capacity utilization rate $\left(1-\Phi\left(z_{i, s}^{\iota}-\sigma_{i}^{\iota}\right)\right) .{ }^{16}$ If $\sigma$ is large, the selection works even immediately after installation, that is, some machines are not used even if they are new. As time passes, the utilization rate gradually declines because these machines are relatively less productive than newer machines. This relationship between vintage and selection holds regardless of the value of $\sigma$, while the pattern is different. If $\sigma$ is small, productivity variation among machines in the same vintage is small. Most of the machines are initially used, and the utilization rate sharply drops once the vintage of machines becomes outdated.

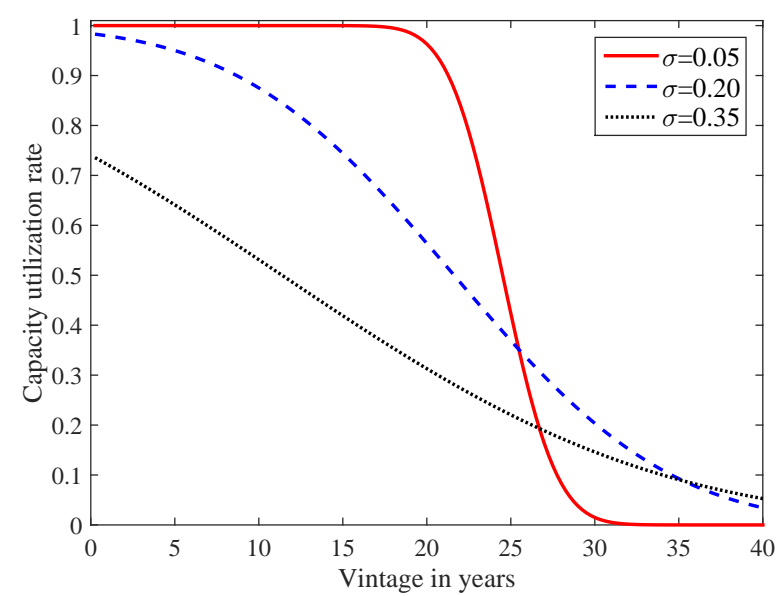

Figure 2: Sigma, vintage, and capacity utilization rates

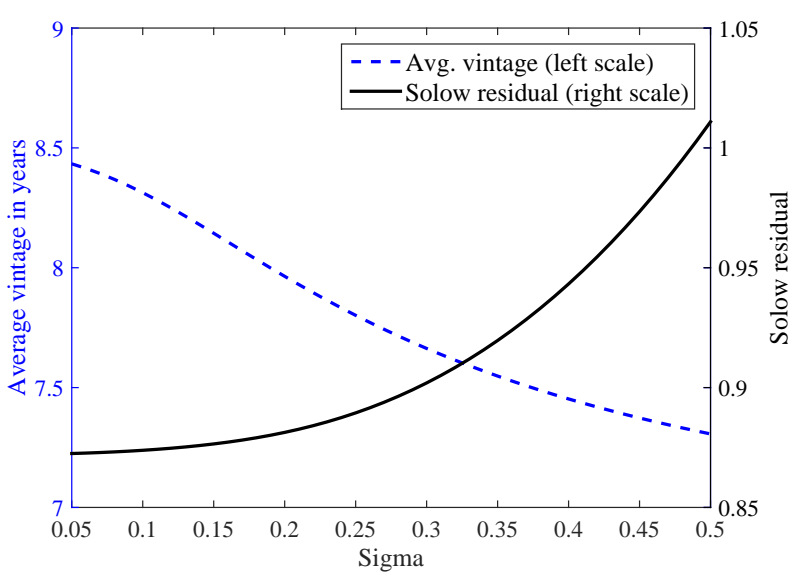

Figure 3: Sigma, average vintage, and Solow residual

\footnotetext{
${ }^{16}$ The calibration strategy basically follows Gilchrist and Williams (2000, 2005). One period of the model is quarter. Parameter values are as follows. The capital-share in the production is $0.3(\alpha=0.3)$. The annual depreciation rate is $8 \%\left(\delta=1-(1-0.08)^{1 / 4}\right)$. The annual trend growth rate is $2 \%\left(g=(1+0.02)^{1 / 4}-1\right)$. The subjective discount factor is determined so that the implied annual real interest rate is $4 \%$ if $g=0$ $\left(\beta=(1 / 1.04)^{1 / 4}\right)$. The share of leisure in the utility function is $0.3(\psi=0.3)$ when I include labor-leisure choice. The mean productivity is set to $1(\theta=1)$.
} 
One important factor implicit in Figure 2 is the exogenous retirement by $\delta$. As time passes, more machines break. The total mass of old machines is not large, however. In Figure 3, the dotted-line with left-axis-scale shows the average vintage of operating machines for different values of $\sigma$. When $\sigma$ is small, most of the machines are active until a certain age. Due to the exogenous retirement, the average vintage is about 8.5 years if $\sigma=0.05$. As $\sigma$ increases, the selection contributes to the industry-level productivity. Less productive machines are not used even in the initial period, and as time passes, more and more machines are replaced by younger machines. The average vintage is even smaller than the case of a small $\sigma$.

The solid-line with right-axis scale of Figure 3 illustrates the relationship between $\sigma$ and the industry-level Solow residual calculated by (44). When $\sigma$ is small, the selection does not contribute to the industry-level productivity. If $\sigma$ is large, the industry-level productivity is observed to be large, thanks to the selection.

In summary, if $\sigma$ is large, the selection eliminates less productive machines from operation. The operating machines are young and more productive, and hence the average vintage of active machines is small. An industry using young machines tends on average to be more productive than other industries.

The rest of the analysis is basically the same as the case of $g=0$. If an industry has higher $\sigma$ than another, the productivity is higher. Observationally, an industry is more productive if the industry uses young machines on average and/or the capacity utilization rate of industry is low. If productivity is high, the relative price of the good is low under autarky. This relative price is an indicator of trade patterns when countries are engaged in trade. 


\section{$3 \quad$ Fixed trade cost and sorting implication}

This section presents an extension of the model. The extended model describes a sorting situation in which the most productive machines export, the moderately productive machines serve the domestic market, and the least productive machines do not operate. Since newer vintage machines are in general more productive, these machines are more likely to be used for exporting. The gains from trade in the extended model are the combined and interactive results of the reallocation across industries by exploiting the comparative advantage, and of the reallocation across machines within an industry.

In Section 2, good $A$ is a pure consumption good, while good $B$ is used both for consumption and investment. To simplify the analysis with fixed trade cost, this section starts from a modified version of the model. Both goods are intermediate inputs used for producing the non-tradeable final goods. The production of the final goods is given by an equally-weighted Cobb-Douglas production function, $\ln Y_{i, t}=0.5 \ln c_{i, t}^{A}+0.5 \ln c_{i, t}^{B}$. The producers of the fi-

nal goods face perfect competition and their profits are $P_{i, t} Y_{i, t}-p_{i, t}^{A} c_{i, t}^{A}-p_{i, t}^{B} c_{i, t}^{B}$. The final goods are used for the consumption and investment, $Y_{i, t}=C_{i, t}+k_{i, t}^{A} q_{i, t}^{A}+k_{i, t}^{B} q_{i, t}^{B}$. Finally, the consumer's period utility is given by the log of consumption and leisure, $u\left(C_{i, t}, L_{i, t}\right)=$ $\psi \ln C_{i, t}+(1-\psi) \ln \left(1-L_{i, t}\right)$.

\subsection{Autarky and costless trade}

The implications of the closed economy or costless trade are almost identical to the previous model; as I discussed in the previous section, demand condition plays a minimal role under autarky and costless trade equilibria. The relative price under autarky is determined by technology. For example, in the closed-economy of $g=0$, the relative price across industries is given by (33).

Under costless trade, the relative price possibly depends on demand condition. If both countries specialize in producing one of the two goods, the relative price is given by a modified 
version of (37). Specifically, the first term, which captures relative demand for two goods, becomes unity due to the symmetry assumption of the two goods.

\subsection{Investment decision}

I introduce a trade cost via fixed labor cost. Namely, to deliver the output $y_{i}^{\iota}(\xi)$ of one machine to the foreign country, the machine requires $1+\tau$ units of domestic labor instead of one unit of labor for the domestic delivery. Owing to this fixed trade cost, price is not equalized across countries.

In the rest of this section, I will focus on a symmetric situation in which one country possesses comparative advantage in one industry, while the other country possesses advantage in the other industry. Moreover, the source of the comparative advantage is purely from the variation term. The mean productivities are assumed to be the same across countries and industries, and variance is symmetric: $\sigma_{1}^{A}=\sigma_{2}^{B}>\sigma_{1}^{B}=\sigma_{2}^{A}$. Under these assumptions, it is sufficient to analyze two types of industries: an industry with comparative advantage (exporting industry) and one without comparative advantage (non-exporting industry). Instead of using country subscripts and industry superscripts, I use superscripts $f, d, o$, and $n$, where $f$ is exported values and foreign prices of exporting industry, $d$ is domestically consumed values and domestic prices of exporting industry, $o$ is exporting industry, and $n$ is non-exporting industry. By considering a case in which country 1 has comparative advantage in good $A$, for example, in country 1, capital-intensity in industry $A$ is attached with $o$ as $k^{o}$. Similarly, $y^{o}$ represents the total production of the exporting industry, and it is sum of the production for domestic supplies $\left(y^{d}\right)$ and foreign supplies $\left(y^{f}\right), y^{o}=y^{d}+y^{f}$. The price of the exporting good in the home country is $p^{d}$, and the price of the exporting good in the foreign country is $p^{f}$. Let $\rho$ be the ratio of the two minus one, $p^{f}=(1+\rho) p^{d}$.

One might think that $\rho=\tau$, (i.e., $\left.p^{f}=(1+\tau) p^{d}\right)$, as is typical in iceberg trade cost

models. However, this is not true. The reason is that if $\rho \geq \tau$, all the machines are used for exporting, and domestic supply is zero. This domestic supply shortfall pushes up the 
domestic price, and shrinks price ratio $\rho$. Hence, an open-economy equilibrium is consistent with $\rho<\tau$.

When $\rho<\tau$, the profits from exporting and domestic sales are different, and machines are sorted by their productivities $\theta^{\circ}(\xi)$. If a machine is sufficiently productive to satisfy

$$
p_{t+s}^{f} \theta_{t}^{o}(\xi) k_{t}^{o \alpha}-(1+\tau) w_{t+s}>p_{t+s}^{d} \theta_{t}^{o}(\xi) k_{t}^{o \alpha}-w_{t+s}
$$

then the machine is used for exporting operation. If a machine is not sufficiently productive to satisfy the inequality but covers operational costs (i.e., wages), it is still used for domestic sales.

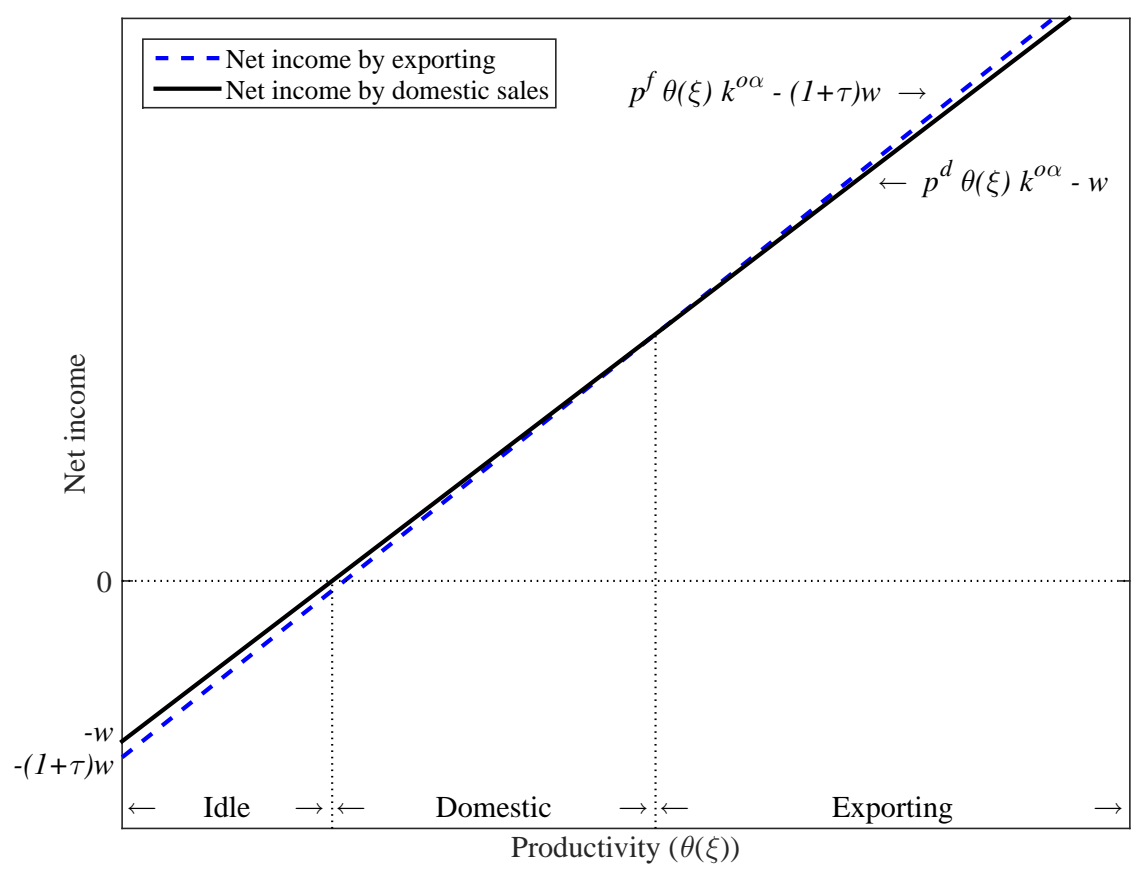

Figure 4: Trade cost, operation decision, and sorting

Figure 4 depicts this sorting situation. The horizontal axis shows the productivity of each machine, and the vertical axis shows the net income from operation. The solid-line shows net income from domestic operation. The machine operates if net income is greater than zero, and is idled if net income is negative. The dotted-line is net income if a machine is used for exporting operation. The net income is negative even at the domestic operational 
cutoff, owing to trade cost. However, if a machine is highly productive, it covers trade costs and earns larger profits from exports than domestic sales. This sorting pattern is closely related to findings in micro-level empirical trade literature (e.g., Bernard and Jensen, 1999).

The investment decision problem takes this sorting into account:

$$
\begin{aligned}
& \max _{k_{t}^{o}}-P_{t} k_{t}^{o}+E_{t}\left[\sum_{s=1}^{\infty} m_{t, t+s}(1-\delta)^{s-1}\right. \\
& \times\left(\int_{\frac{\tau w_{t+s}}{\rho_{t+s} p_{t+s}^{d} k_{t}^{o \alpha}}}^{\infty}\left(p_{t+s}^{f} \theta_{t}^{o}(\xi) k_{t}^{o \alpha}-(1+\tau) w_{t+s}\right) f_{\Theta}\left(\theta_{t}^{o}(\xi) \mid w_{t+s}, p_{t+s}^{d}, p_{t+s}^{f}, \theta_{t}^{o}\right) d \theta_{t}^{o}(\xi)\right. \\
& \left.\left.+\int_{\frac{w_{t+s}}{p_{t+s}^{d} k_{t}^{o \alpha}}}^{\frac{\tau w_{t+s}}{\rho_{t+s} p_{t+s}^{o} k_{t}^{o \alpha}}}\left(p_{t+s}^{d} \theta_{t}^{o}(\xi) k_{t}^{o \alpha}-w_{t+s}\right) f_{\Theta}\left(\theta_{t}^{o}(\xi) \mid w_{t+s}, p_{t+s}^{d}, p_{t+s}^{f}, \theta_{t}^{o}\right) d \theta_{t}^{o}(\xi)\right)\right] .
\end{aligned}
$$

For each vintage $s$, there are two cut-offs, $z_{s}^{d}$ for domestic operation, and $z_{s}^{f}$ for exporting. As shown in the Appendix, on the balanced growth path, two cutoffs are linked by $z_{s}^{f}=$ $z_{s}^{d}+\frac{1}{\sigma^{o}} \ln (\tau / \rho)$. In the case of $g=0$, two cutoffs $z^{d}$ and $z^{f}$ are summarized by the following equation, which is an extension of (27):

$$
1-\alpha=\frac{\rho}{\tau} \frac{\phi\left(z^{f}-\sigma^{o}\right)}{\phi\left(z^{f}\right)} \frac{\tau\left(1-\Phi\left(z^{f}\right)\right)+1-\Phi\left(z^{d}\right)}{\rho\left(1-\Phi\left(z^{f}-\sigma^{o}\right)\right)+1-\Phi\left(z^{d}-\sigma^{o}\right)} .
$$

Note that $\rho$ is an endogenous variable, which ultimately depends on $z^{f}$. Hence, the equilibrium is a fixed point for solving $\rho, z^{d}$ and $z^{f}$, which are consistent with (47) and other steady-state equilibrium conditions. If $g>0$, a condition extending (47) includes $z_{s}^{d}$ and $z_{s}^{f}$ (see the Appendix), but the equilibrium is similarly calculated.

I solve the equilibrium numerically. ${ }^{17}$ The mean productivities are $\theta^{o}=\theta^{n}=\theta_{i}^{\iota}=1$ for all $i$ and $\iota$. Gilchrist and Williams (2005) set $\sigma=0.2$ for their baseline analysis. Here I set $\sigma^{o}\left(=\sigma_{1}^{A}=\sigma_{2}^{B}\right)=0.35$, and $\sigma^{n}\left(=\sigma_{1}^{B}=\sigma_{2}^{A}\right)=0.15$. From the results obtained in the previous sections, country 1 possesses comparative and absolute advantages for producing good $A$, and country 2 possesses comparative and absolute advantages for producing good

\footnotetext{
${ }^{17}$ See footnote 16 for other parameter values.
} 
$B$. For trade cost, I examine the range of $\tau$ between 0 and 0.2 . Under this parameterization, it turns out that $\tau=0.2$ gives results almost identical to those of autarky equilibrium.

\subsection{Vintage, productivity, and operating status}

Figure 5 shows the distribution of machines of an exporting industry. The vertical axis shows quantity of machines, while the horizontal axis shows the labor-productivity of machines, which is the product of idiosyncratic productivity $(\theta(\xi))$, the contribution of trend growth $(1+g)^{-s}$, and capital-intensity $\left(k^{\alpha}\right)$. The distribution of newly installed machines (the solid line) is on the right of the distributions of 10-year and 20-year-old machines indicated by, respectively, the broken and dotted lines. New (small $s$ ) machines are, in general, more productive than old (large $s$ ) machines. The quantity of machine of old machine is small, reflecting the exogenous retirement.

New machines are more productive, and hence these are more likely to be in operation. Furthermore, among new machines, top-tier machines are used for exporting. Old machines are not only few due to retirement but also less productive due to embodied vintage technology. This sorting for different vintages is also illustrated by Figure 6, which shows the relationship between vintage and operational status. The figure shows that among new machines, approximately the top $5 \%$ are used for exporting, the middle $70 \%$ are used for domestic supply, and the bottom $25 \%$ are idle. The fractions of exporting and domestic supply decrease as machines age. Among 20-year-old machines, the top $35 \%$ are in operation, but almost none of these machines are used for exporting. ${ }^{18}$

From these figures, the model predicts that (1) more productive machines are more likely used for exporting, (2) newer machines are more likely used for exporting, (3) if an old machine is used for exporting, the machine was initially extremely productive.

In the light of the literature, (1) is routinely described using a type of Melitz (2003) model. However, the baseline Melitz (2003) model is silent about the relationship between opera-

\footnotetext{
${ }^{18}$ These numbers depend on parameters, but qualitative implications are robust under reasonable calibrations.
} 


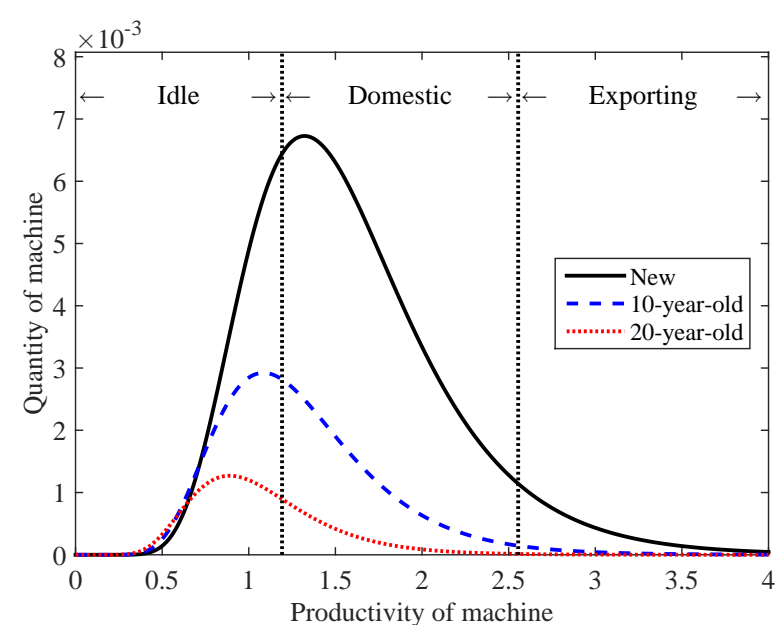

Figure 5: Distribution of machines

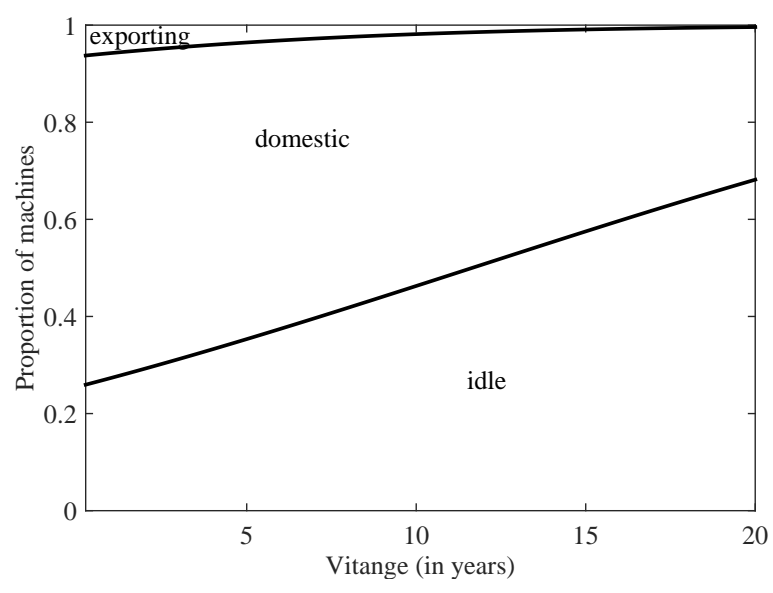

Figure 6: Vintage and and operation status

tional status and vintage. My model offers new insights regarding vintage and operational status.

In this model, a unit of production is a machine. An empirical problem is how to map the model to data. A simple approach is to consider this production unit as a firm (or plant). Then, the model's prediction regarding operational status of a machine is regarded as operational status of the firm. Another, and probably more reasonable, approach is to think that firm is a collection of multiple machines.

A simple way to include a firm in the model is to follow a three-step procedure. First, in each period, households determine the total investment of capital-intensity and number of machines. Second, each firm draws from a lottery, which specifies the number of machines to be installed for each firm. Third, idiosyncratic productivity is assigned for each machine. If financial and labor markets are perfect, the investment decision of the households is purely determined by the stochastic discount factor, and is independent from the inter-firm allocations. Then, the aggregate properties of the equilibrium are the same as the previous analysis. In this world, some firm have many machines, while other firms have only a few machines. Some firms have new and productive machines, other firms have old but productive machines, and still other firms have old and unproductive machines.

This modified model gives not only standard but also several new predictions regarding 
the firm characteristics and exporting status. The model predicts that the standard relationship between productivity and operation status: (4) more productive firms are likely exporters, and (5) export intensity is higher for more productive firms. In addition, the model provides three new predictions with respect to the vintage of machines and exporting status: (6) a firm with newer vintage machines is more likely to be an exporter, (7) among exporters, export intensity is higher for the firm with newer vintage machines, and (8) a firm starts exporting after an installation of new and productive machines. ${ }^{19}$ Future investigations to test these predictions are expected.

\subsection{Welfare effects of trade cost reduction}

There are two possible types of equilibrium. One is that both countries completely specialize. This equilibrium is realized if trade cost is small. In particular, if trade cost is zero, the situation is then exactly the same as costless trade equilibrium. The other equilibrium exists when both countries produce both goods. This is the case if trade cost is large. When trade cost is extremely large, the model is effectively the same as autarky. As trade cost decreases, highly productive machines start to export (as described by Figure 4). However, since the total number of such productive machines is small, the supply of exporting goods is smaller than the demand. This imbalance drives up the price of the goods, and stimulates domestic production. That is, a country lacking comparative advantage in this good continues to produce.

Figure 7 shows the realized equilibrium values for different fixed trade cost $\tau$. In the panels, the horizontal axis represents values of $\tau$, while the vertical axis represents other variables. If $\tau=0$, the economy is the same as the costless trade. Similarly, if $\tau$ is large, the economy is effectively the same as autarky.

The top-left panel of Figure 7 shows the utilization ratios of newly installed machines $(s=1)$ for various operations (ratio of activated, domestic, and exporting operation to total

\footnotetext{
${ }^{19}$ I extend appreciatation to one of the referees for encouraging me to include capital-embodied technology progress, and suggesting implications (6) and (7).
} 

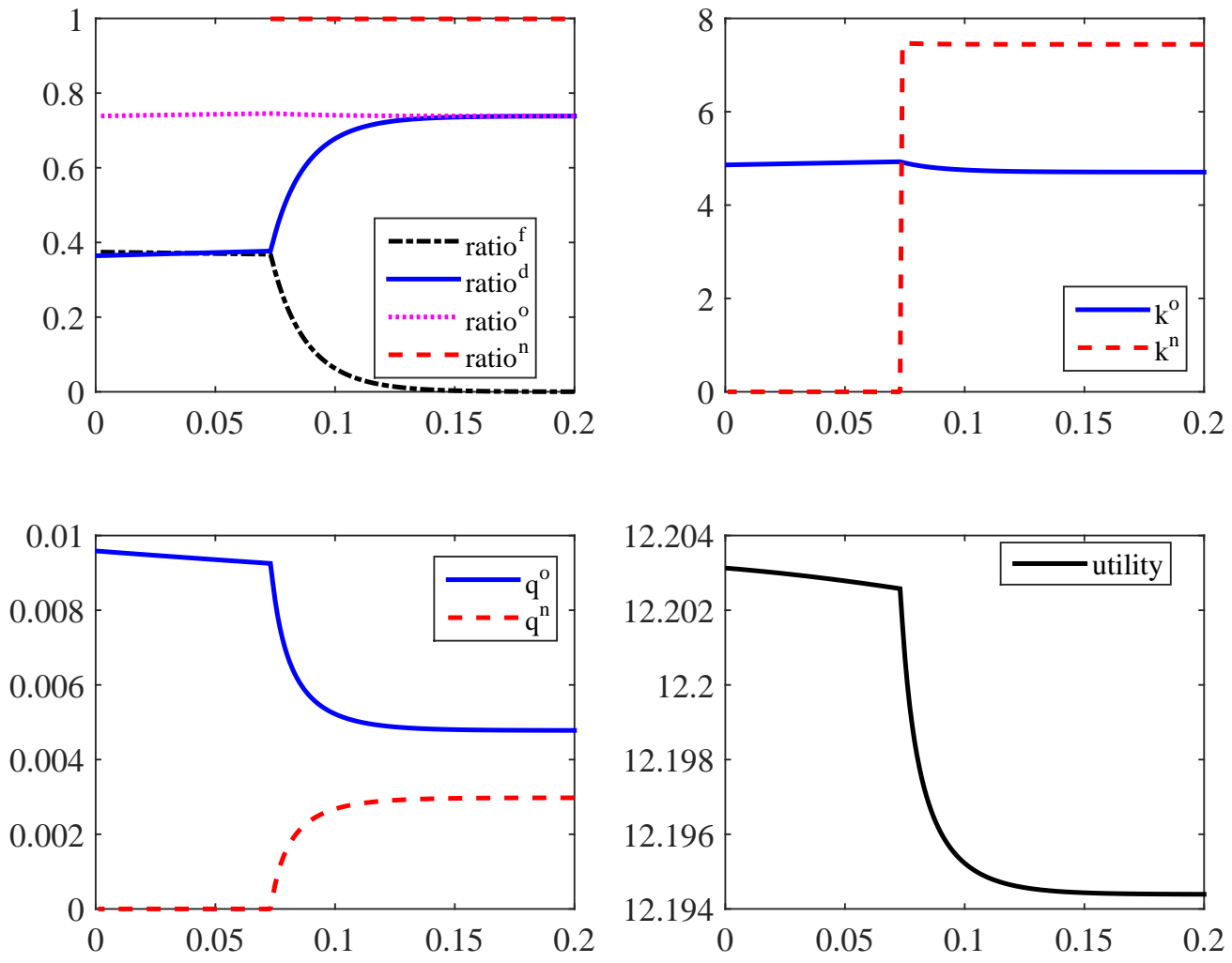

Figure 7: Effects of change in trade costs

existing machines of the vintage). Under autarky $(\tau=0.2)$, no machines are used for exporting operation ( ratio $^{f}$, the dash-dotted-line). As trade cost decreases, more machines are used for exporting, and fewer are used for domestic supply ( ratio $^{\mathrm{d}}$, the solid-line). Capacity utilization rate of this industry $\left(\right.$ ratio $^{\circ}\left(=\right.$ ratio $^{\mathrm{f}}+$ ratio $^{\mathrm{d}}$, the dotted-line) increases as $\tau$ decreases until a critical value, and then silightly decreases. This critical value divides the two types of equilibria, whether $n$-industry is active or not. The utilization ratio of machines used in $n$-industry $\left(\right.$ ratio $^{\mathrm{n}}$ ) is high (approximately 0.999$)$ when the industry is active.

The top-right panel of Figure 7 shows the capital-intensity of $o$ - and $n$-industry, and the bottom-left panel shows the quantities of machines. Starting from autarky (right-end), the capital-intensity of $o$-industry ( $k^{o}$, the solid-line) gradually increases as trade cost decreases, and then decreases. As trade cost decreases, more resources are available for o-industry. A rapid increase in the machines used for exporting is accompanied by a rapid increase in investment in $o$-industry. The capital-intensity of $n$-industry ( $k^{n}$, the dashed-line) remains 
nearly flat until the critical value. Under autarky, the capital-intensity is higher in $n$-industry than in $o$-industry, as discussed in Section 2.

The quantity of machines of $n$-industry $\left(q^{n}\right)$ gradually decreases as trade cost decreases. Since more foreign products are supplied, the production of $n$-goods in this country decreases. This internal supply adjustment occurs through the number of machines since capital-intensity of this industry remains unchanged. In this phase, a source of aggregate welfare gain is this inter-industry reallocation.

Once the inter-industry reallocation ends, and two countries completely specialize, the selection among machines is the only source of industry-level productivity gain. As trade cost decreases, capacity utilization rate decreases capital-intensity decreases and the number of machines increases.

A reduction in trade cost definitely increases welfare, but how it changes depends on the specialization phases. As shown in the bottom-right panel of Figure 7, the utility monotonically increases as trade cost decreases. The change in the phase changes the slope of the curve. In particular, the welfare gain is largest in the timing of large increase in exporting.

In summary, a reduction of trade cost has two different types of impacts: inter-industry reallocation and intra-industry reallocation. Starting from autarky, a reduction in trade cost causes inter-industry reallocation. More machines are created in the comparative advantage industry. The pattern is further amplified by an increase in the capital-intensity of this industry. At the same time, relatively less productive machines are also activated in the industry with comparative advantage. Once countries completely specialize, less productive machines fall idle. This change of the phase leads to a nonlinear impact of trade cost reduction on welfare. Since nonlinearity is not considered in models analyzed by Arkolakis et al. (2012), their finding that gains from trade are unexpectedly low in the standard trade models might, indeed, be explained by the role of nonlinearlity. Exploring this possibility is an important future research topic. 


\section{Conclusion}

This paper considers the role of investment and heterogeneity in productivity across capital goods on the pattern of international trade. Specifically, I introduce putty-clay production technology in the style of Gilchrist and Williams (2000, 2005) into an international trade model considered by Baxter (1992).

Motivated by several micro-studies, I assume capital goods are heterogeneous due to idiosyncratic productivity variation and vintage. In a two-country, two-good, two-factor model, trade pattern is generally described by Ricardian comparative advantage. However, I find a new source of comparative advantage: the magnitude of capital goods heterogeneity. A country has comparative advantage in an industry with relatively larger capital goods variation. Accordingly, the model predicts that an industry is more likely to have comparative advantage if the industry uses on average new machines, the industry's capital utilization rate is low, and capital goods in the industry has large productivity variation.

With fixed trade cost, the model describes a sorting situation in which the most productive machines (which are generally newer vintage) export, the moderately productive machines serve the domestic market, and the least productive machines (old) do not operate. The model gives novel predictions regarding vintage and exporting status: a firm with newer vintage machines is more likely to be an exporter, among exporters, export intensity is higher for the firm with newer vintage machines, and a firm starts exporting after an installation of new and productive machines. The gains from trade are the combined and interactive results of the reallocation across industries by exploiting the comparative advantage, and of the reallocation across production units within an industry. As a result, a change in the trade cost has nonlinear implications on the change in the welfare.

The steady-state implications of the investment decision and the aggregation results of the putty-clay model are sufficiently simple to incorporate a Ricardian model, although the underlying investment decision is sufficiently rich to capture the essential features of capital goods heterogeneity. This paper presents an extension including fixed cost, and there are 
many possibilities to extend the model. One direction is to apply the framework to human capital investment instead of physical capital investment. Future research is expected.

\section{References}

Antràs, P., L. Garicano, and E. Rossi-Hansberg (2006): "Offshoring in a Knowledge Economy," Quarterly Journal of Economics, 121, 31-77.

Arkolakis, C., A. Costinot, and A. Rodríguez-Clare (2010): "Gains from Trade under Monopolistic Competition: A Simple Example with Translog Expenditure Functions and Pareto Distributions of Firm-Level Productivity," mimeo.

(2012): "New Trade Models, Same Old Gains?" American Economic Review, 102, $94-130$.

Atkeson, A. And P. J. Kehoe (1999): "Models of Energy Use: Putty-Putty versus Putty-Clay," American Economic Review, 89, 1028-1043.

Baxter, M. (1992): "Fiscal Policy, Specialization, and Trade in the Two-Sector Model: The Return of Ricardo?" Journal of Political Economy, 100, 713-744.

Behrens, K. And Y. Murata (2011): "Trade, Competition, and Efficiency," Journal of International Economics, 87, 1-17.

Bernard, A. B., J. Eaton, J. B. Jensen, And S. Kortum (2003): "Plants and Productivity in International Trade," American Economic Review, 93, 1268-1290.

Bernard, A. B. And J. B. Jensen (1997): "Exporters, Skill Upgrading, and the Wage Gap," Journal of International Economics, 42, 3-31.

(1999): "Exceptional Exporter Performance: Cause, Effect, or Both?" Journal of International Economics, 47, 1-25. 
Bernard, A. B., S. Redding, And P. K. Schott (2007): "Comparative Advantage and Heterogeneous Firms," Review of Economic Studies, 74, 31-66.

Birchenall, J. (2004): "Capital Accumulation, Unemployment, and the Putty-clay," Economics Bulletin, 5, 1-8.

Bougheas, S. And R. Riezman (2007): "Trade and the Distribution of Human Capital," Journal of International Economics, 73, 421-433.

Campbell, J. R. (1998): "Entry, Exit, Embodied Technology, and Business Cycles," Review of Economic Dynamics, 1, 371-408.

Choi, S. And J. Rios-Rull (2012): "Labor Share and Technology Dynamics," mimeo.

Cobb, C. W. And P. H. Douglas (1928): "A Theory of Production," American Economic Review, 18, 139-165.

Cooper, R. W. And J. C. Haltiwanger (2006): "On the Nature of Capital Adjustment Costs," Review of Economic Studies, 73, 611-633.

Costinot, A. (2009): "An Elementary Theory of Comparative Advantage," Econometrica, 77, 1165-1192.

Eaton, J. (1979): "The Allocation of Resources in an Open Economy with Uncertain Terms of Trade," International Economic Review, 20, 391-403.

Eaton, J. And S. Kortum (2002): "Technology, Geography, and Trade," Econometrica, 70, 1741-1779.

Feenstra, R. C. (2004): Advanced International Trade, Princeton, NJ: Princeton University Press. 
Foster, L., J. Haltiwanger, And C. Syverson (2008): "Reallocation, Firm Turnover, and Efficiency: Selection on Productivity or Profitability," American Economic Review, 98, 394-425.

Fuss, M. A. (1977): "The Structure of Technology over Time: A Model for Testing the 'Putty-Clay' Hypothesis," Econometrica, 45, 1797-1821.

Gilchrist, S. And J. C. Williams (2000): "Putty-Clay and Investment: A Business Cycle Analysis," Journal of Political Economy, 108, 928-960.

(2004): "Transition Dynamics in Vintage Capital Models: Explaining the Post-war Experience of German and Japan," mimeo.

— (2005): "Investment, Capacity, and Uncertainty: A Putty-Clay Approach," Review of Economic Dynamics, 8, 1-27.

Goolsbee, A. (2004): "Taxes and the Quality of Capital," Journal of Public Economics, 88, 519-543.

Goolsbee, A. And D. B. Gross (2000): "Estimating the Form of Adjustment Costs with Data on Heterogeneous Capital Goods," mimeo.

Gourio, F. (2011): "Putty-Clay Technology and Stock Market Volatility," Journal of Monetary Economics, 58, 117-131.

Greenwood, J., Z. Hercowitz, and G. W. Huffman (1988): "Investment, Capacity Utilization, and the Real Business Cycle," American Economic Review, 78, 402-417.

Grossman, G. M. (1983): "Partially Mobile Capital: A General Approach to Two-sector Trade Theory," Journal of International Economics, 15, 1-17.

Grossman, G. M. And G. Maggi (2000): "Diversity and Trade," American Economic Review, 90, 1255-1275. 
Houthakker, H. S. (1955-56): "The Pareto Distribution and the Cobb-Douglas Production Function in Activity Analysis," Review of Economic Studies, 23, 27-31.

InADA, K. (1966): "Investment in Fixed Capital and the Stability of Growth Equilibrium," Review of Economic Studies, 33, 19-30.

Jensen, J. B., R. H. McGuckin, And K. J. Stiroh (2001): "The Impact of Vintage and Survival on Productivity: Evidence from Cohorts of U.S. Manufacturing Plants," Review of Economics and Statistics, 83, 323-332.

Johansen, L. (1959): "Substitution versus Fixed Production Coefficients in the Theory of Economic Growth: A Synthesis," Econometrica, 27, 157-176.

- (1972): Production Functions: An Integration of Micro and Macro, Short Run and Long Run Aspects, North-Holland.

Jones, C. I. (2011): "Intermediate Goods and Weak Links in the Theory of Economic Development," American Economic Journal: Macroeconomics, 3, 1-28.

Kremer, M. (1993): "The O-Ring Theory of Economic Development," Quarterly Journal of Economics, 108, 551-575.

Lagos, R. (2006): "A Model of TFP," Review of Economic Studies, 73, 983-1007.

Lasserre, P. (1985): "Capacity Choice by Mines," Canadian Journal of Economics, 18, $831-842$.

Melitz, M. J. (2003): "The Impact of Trade on Intra-Industry Reallocations and Aggregate Industry Productivity," Econometrica, 71, 1695-1725.

Ohnsorge, F. And D. Trefler (2007): "Sorting It Out: International Trade with Heterogeneous Workers," Journal of Political Economy, 115, 868-892. 
Salvanes, K. G. And R. Tveteras (2004): "Plant Exit, Vintage Capital and the Business Cycle," Journal of Industrial Economics, 52, 255-276.

TomiurA, E. (2007): "Foreign Outsourcing, Exporting, and FDI: A Productivity Comparison at the Firm Level," Journal of International Economics, 72, 113-127.

WeI, C. (2003): "Energy, the Stock Market, and the Putty-Clay Investment Model," American Economic Review, 98, 311-323. 